\title{
HUBUNGAN STRES DENGAN KEJADIAN HIPERTENSI DI WILAYAH KERJA PUSKESMAS SEI PANCUR KOTA BATAM TAHUN 2018
}

\author{
Asfri Sri Rahmadeni, Lela Fajar, Nahrul Hayat \\ (Prodi DIII Keperawatan, STIKes Mitra Bunda Persada Batam)
}

\begin{abstract}
Hypertension is a condition in which blood pressure increases persistently which is ranked number one cause of death each year. It is estimated that in 2025 there will be 1.5 billion people suffering from hypertension, this problem occurs in many developed and developing countries. The purpose of this study was to determine the relationship of stress with the incidence of hypertension at the Sei Pancur Health Center in Batam City in 2018. The research method used analytical design with a cross sectional design. The sampling technique of this study used non-probability sampling technique with purposive sampling totaling 61 samples. The results of this study found that the stress experienced was in very heavy stress the majority of $62.3 \%$ of respondents, the majority of $91.8 \%$ of respondents experienced hypertension. The results of the analysis there is a relationship between stress and the incidence of hypertension with a value of $\rho=0.001<0.05$. Based on this, it is recommended that health services improve health care problems, especially problems that cause hypertension.
\end{abstract}

Keywords: Hypertension,Blood, Stress

\section{PENDAHULUAN}

Hipertensi merupakan penyakit degeneratif yang menjadi masalah serius saat ini. Hipertensi dikategorikan sebagai the silent disease atau the silent killer karena penderita tidak mengetahui dirinya mengidap hipertensi atau tidak mengetahui sebelum memeriksakan hipertensinya. Insiden hipertensi meningkat seiring bertambahnya usia. Bahaya hipertensi yang tidak dapat dikendalikan dapat menimbulkan komplikasi yang berbahaya, seperti penyakit jantung koroner, stroke, ginjal dan gangguan penglihatan. Kematian akibat hipertensi menduduki peringkat atas daripada penyebab-penyebab lainnya (Bambang, 2014).

Menurut American Heart Association (AHA) penduduk Amerika yang berusia diatas 20 tahun menderita hipertensi telah mencapai angka hingga 74,5 juta jiwa, namun hampir sekitar 90-95\% kasus tidak diketahui penyebabnya. Hipertensi merupakan silent killer dimana gejala dapat bervariasi pada masing-masing individu dan hampir sama dengan gejala penyakit lainnya. Gejala- gejalanya itu adalah sakit kepala/rasa berat ditengkuk, mumet (vertigo), jantung berdebar-debar, mudah lelah, penglihatan kabur, telinga berdenging(tinitus), dan mimisan.

Tekanan darah didunia terus akan meningkat setiap tahunnya, diperkirakan pada 2025 akan ada 1,5 miliar orang yang terkena hipertensi. Di perkirakan juga setiap tahunnya ada 
9,4 juta orang yang meninggal akibat hipertensi dan komplikasinya seperti stroke (51\%) dan penyakit jantung coroner (45\%) (Kemenkes, 2017).

Pengukuran tekanan darah pada pengunjung pelayanan kesehatan yang di puskesmas dan rumah sakit se Kepulauan Riau menemukan kasus Hipertensi sebanyak 98620 penyakit tertinggi ketiga dari 10 penyakit terbesar yang terdapat di kepulauan riau kota batam (Profil kesehatan kepri, 2017).

Penelitian ini dilakukan oleh ahmad khairudin (2015) tentang hubungan stres dengan hipertensi anggota polri disekolah polisi Negara selopamioro Yogyakarta 2015, didapatkanhasil penelitian pada tingkat stres mayoritas memiliki kategori tinggi sebanyak 8 orang $(44,4 \%)$, sedangkan paling sedikit kategori rendah sebanyak 3 orang $(16,7 \%)$. Penelitian ini juga sejalan dengan penelitian yang dilakukan oleh Basmanelly, dan Huriani(2014), tentang hubungan tingkat stres dengan derajat hipertensi pada pasien hipertensi di wilayah kerja puskesmas andalas padang bahwa hasil penelitian menunjukkan bahwa terdapat hubungan yang signifikan antara tingkat stres dengan derajat hipertensi pada pasien hipertensi di wilayah kerja Puskesmas Andalas Padang Tahun 2014.

Dampak stresakan menimbulkan perubahan dalam tubuh, selain itu, stres juga berpengaruh dalam emosi. Beberapa gejala stres di antaranya denyut jantung cepat, nyeri kepala, kaku leher, dan nyeri punggung, nafas cepat. Stres juga mempengaruhi system kekebalan tubuh stres yang terus menerus dapat membuat orang mudah untuk jatuh sakit. Sebaiknya mengupayakan mengatasi stres, karena selain dapat menyebabkan hipertensi, juga dapat meningkatkan resiko terkena penyakit lainnyaseperti stroke, ginjal kronik (Wade, 2016).

Berdasarkan masalah hipertensi diatas, salah satu solusi yang diterapkan untuk mengontrol hipertensi dalam program pemerintahan melaksanakan program Indonesia sehat dengan pendekatan keluarga (PIS-KIS) dan gerakan masyarakat hidup sehat (Germas). Harapannya, seluruh komponen bangsa dengan sadar mau membudayakan perilaku hidup sehat dimulai dari keluarga.

\section{METODE PENELITIAN}

Penelitian ini menggunakan desain analitik dengan rancangan cross sectional. dilaksanakan di wilayah kerja Pukesmas Sei Pancur pada bulan Agustus-September 2018 Kota Batam. Populasi seluruh penderita hipertensi yang berkunjung ke puskesmas sei pancur berjumlah 61 responden menggunakan teknik non-probability sampling dengan pengukuran langsung pada tekanan darah. Uji statistic ini untuk melihat hubungan antara stres dengan kejadian hipertensi di Kota Batam, data dianalisis dengan menggunakan uji Mann-whitney dengan Hasil analisis terdapat hubungan stress dengan kejadian hipertensi dengan nilai $\rho=0,001<0,05$.

Penerbit: Poltekkes Kemenkes Padang, http://jurnal.poltekkespadang.ac.id/ojs/index.php/jsm 


\section{HASIL PENELITIAN}

\section{Analisa Univariat}

Karateristik Responden

Tabel 4.1 Distibusi Frekuensi Berdasarkan Umur di Wilayah Kerja Puskesmas Sei Pancur Kota Batam Tahun 2018

\begin{tabular}{|c|c|c|}
\hline Umur & frekuensi & Persentase \% \\
\hline Dewasa Awal & 11 & 18 \\
\hline Dewasa Akhir & 50 & 82 \\
\hline Total & 61 & 100 \\
\hline
\end{tabular}

Berdasarkan Tabel 4.1 menunjukkan bahwa usia pada penelitian ini mayoritas berada dalam kategori dewasa akhir dengan jumlah 50 (82\%).

Tabel 4.2 Distribusi Frekuensi Berdasarkan Jenis Kelamin Di Wilayah Kerja Puskesmas Sei Pancur Kota Batam Tahun 2018

\begin{tabular}{ccc}
\hline Jenis Kelamin & frekuensi & Persentase \% \\
\hline Laki-laki & 24 & 37,7 \\
\hline Perempuan & 37 & 62,3 \\
\hline Total & 61 & 100 \\
\hline
\end{tabular}

Berdasarkan tabel 4.2 menunjukkan bahwa jenis kelamin pada penelitian ini mayoritas berjenis kelamin perempuan dengan jumlah $37(60,7 \%)$

Tabel 4.3 Distribusi Frekuensi Berdasarkan Pekerjaan Di Wilayah Kerja Puskesmas Sei Pancur Kota Batam Tahun 2018

\begin{tabular}{ccc}
\hline Pekerjaan & frekuensi & Persentase $\%$ \\
\hline Wiraswasta & 23 & 37,7 \\
\hline Swasta & 38 & 62,3 \\
\hline Total & 61 & 100 \\
\hline
\end{tabular}

Berdasarkan tabel 4.3 menunjukkan bahwa pekerjaan pada penelitian ini mayoritas sebagai swasta dengan jumlah 38 (62,3\%).

Tabel 4.4 Distribusi Frekuensi Berdasarkan Stres di Wilayah Kerja Puskesmas Sei Pancur Kota Batam Tahun 2018

\begin{tabular}{ccc}
\hline Stres & frekuensi & Persentase $\%$ \\
\hline Normal & 1 & 1,6 \\
\hline Ringan & 4 & 6,6 \\
\hline Sedang & 5 & 8,2 \\
\hline Berat & 11 & 18,0 \\
\hline Sangat berat & 40 & 65,6 \\
\hline Total & 61 & 100 \\
\hline
\end{tabular}


Berdasarkan tabel 4.4 menunjukkan bahwa stres mayoritas berada pada kategori stres sangat berat dengan jumlah 40 (62,3\%).

Tabel 4.5 Distribusi Frekuensi Berdasakan Hipertensi Di Wilayah Kerja Puskesmas Sei Pancur Kota Batam Tahun 2018

\begin{tabular}{ccc}
\hline Kejadian Hipertensi & frekuensi & Persentase \% \\
\hline Hipertensi & 56 & 91,8 \\
\hline Tidak hipertensi & 5 & 8,2 \\
\hline Total & 61 & 100 \\
\hline
\end{tabular}

Berdasarkan tabel 4.5 menunjukkan bahwa hipertensi mayoritas berada pada kategori hipertensi dengan jumlah 56 (91,8\%).

\section{Analisa Bivariat}

Tabel 4.6 Hubungan stres dengan kejadian hipertensi di Wilayah Kerja Puskesmas Sei Pancur Kota Batam Tahun 2018

\begin{tabular}{|c|c|c|c|c|c|c|c|}
\hline & & \multicolumn{4}{|c|}{ Kejadian Hipertensi } & \multirow{2}{*}{ Total } & \multirow[b]{2}{*}{$\%$} \\
\hline & & & & & idak & & \\
\hline & Normal & 1 & $100 \%$ & 0 & $0 \%$ & 1 & 100 \\
\hline & stresringan & 2 & $50 \%$ & 2 & $50 \%$ & 4 & 100 \\
\hline \multirow[t]{3}{*}{ stres } & stressedang & 4 & $80 \%$ & 1 & $20 \%$ & 5 & 100 \\
\hline & stresberat & 9 & $81,8 \%$ & 2 & $18,2 \%$ & 11 & 100 \\
\hline & $\begin{array}{l}\text { Stress sangat } \\
\text { berat }\end{array}$ & 40 & $100 \%$ & 0 & $0 \%$ & 40 & 100 \\
\hline Total & & 56 & $91,8 \%$ & 5 & $5 \%$ & 61 & 100 \\
\hline
\end{tabular}

Berdasarkan Tabel 4.6 di dapatkan hasil bahwa, pada stres normal pasien yang mengalami hipertensi sebanyak 1 orang (100\%), pada stres ringan yang mengalami hipertensi 2 orang $(50 \%)$, pada stres sedang yang mengalami hipertensi 4 orang $(80 \%)$, pada stres berat yang pasien mengalami hipertensi sebanyak 9 orang $(81,8 \%)$, pada stres berat mayoritas yang mengalami hipertensi sebanyak 40 responden $(91,8 \%)$.

Berdasarkan hasil analisa table dengan menggunakan Man whitney $U$ diperoleh nilai ( $p$ value $)=0.001(<0.05)$. hal ini menunjukkan bahwa ada hubungan yang bermakna antara Stres dengan kejadian hipertensi di Puskesmas Sei Pancur Kota Batam tahun 2018.

\section{PEMBAHASAN}

\section{Stres}

Berdasarkan tabel 4.6 memperlihatkan bahwa reponden yang memiliki stress normal 1 responden $(1,6 \%)$, stress ringan 4 responden $(6,6 \%)$, stressedang 5 responden $(8,2 \%)$, stress berat 11 responden (18,0\%), stress sangat berat 40 responden (65,6\%). Hasil 
penelitian juga melihatkan bahwa stress banyak terdapat pada umur dewasa akhir yang berjenis kelamin perempuan dan bekerja sebagai pegawai swasta.

Secara teori Umumnya wanita lebih mudah mengalami stress dari pada pria. Secara fisiologis, otak wanita lebih kecil daripada otak pria. Meskipun begitu, otak wanita bekerja 78 kali lebih keras dibandingkan pria pada saat mengalami masalah. Selain itu, wanita selalu membuat satu permasalahan menjadi kompleks, karena adanya jembatan pada otak kanan dan otak kiri yang bernama corpus colasum yang lebih tebal dan lebih banyak $30 \%$ dari pada otak pria. inilah yang memungkinkan bahwa wanita lebih gampang stres karena wanita lebih mudah menghubungkan satu hal dengan hal lainnya.

Stress sangat tergantung dengan stressor yang menimpanya. Salah satu stressor yang menyebabkan stress adalah social psikologik, yaitu labeling (penamaan) dan prasangka, ketidak puasan terhadap diri sendiri, pekerjaan (aniaya, perkosaan), konflikperan, percayadiri yang rendah, perubahan ekonomi, emosi yang negatif, dankehamilan (Rasmun, 2004 dalam sartika, 2014). Stress dapat di definisikan sebagai sebuah keadaan yang kita alami ketika ada sebuah ketidak sesuaian antara tuntutan yang diterima dan kemampuan untuk mengatasinya (Looker dan Gregson,2005), Hal ini sesuai dengan penelitian yang di lakukan Katerin Indah Islami, 2015 yang menyatakan sebanyak 33 (70.2\%) responden yang mengalami stress.

\section{Hipertensi}

Hasil penelitian didapatkan jumlah mayoritas di puskesmas sei pancur kota batam yang menderita hipertensi sebanyak 56 orang $(91,8 \%)$, mayoritas yang menderita hipertensi mayoritas adalah dewasa akhir 38-45 tahun sebanyak 11 responden (18\%). Pembuluh darah mulai melemah dan dinding pembuluh darah sudah menebal baik pria maupun wanita $50 \%$ dari mereka yang berusia di atas 30 akan menderita hipertensi sistolik menurut (Grey,2014).

Hal ini sejalan dengan penelitian (Artiyaningrum,2015) mengenai faktor faktor yang berhubungan dengan kejadian hipertensi pada penderita yang melakukan pemeriksaan rutin di puskesmas Kedung mundu yang menyatakan ada hubungan antara umur dengan kejadian hipertensi dengan pvalue $0,025=<0,05$.

\section{Hubungan stres dengasn kejadian hipertensi di Puskemas Sei Pancur Kota Batam}

Berdasarkan hasil penelitian diketahui bahwa stres di puskesmas Sei Pancur Kota Batam Tahun 2018 mayoritas yang mengalami stres berat berjumlah 40 orang (65.6\%). Pasien yang mengalami stres mayoritas perempuan dengan jumlah 37 responden $(62,3 \%)$

Penelitian ini sejalan dengan penelitian yang di lakukan oleh Yimmi Syavardie (2014) pengaruh stres terhdap kejadian hipertensi di puskesmas matur, kabupaten agam bahwa mayoritas responden mengalami stres sangat berat 43 orang $(61,4 \%)$. 
Menurut Handriani (2013) bahwa hipertensi pada wanita seringkali dipicu oleh perilaku tidak sehat seperti kelebihan berat badan, stres, rendahnya status pekerjaan, dan penggunaan kontrasepsi hormonal.

Stres merupakan kondisi dimana tubuh menghasilkan hormon adrenaliln lebih banyak, membuat jantung bekerja lebih kuat dan cepat. Apabila terjadi dalam jangka waktu yang lama maka akan menimbulkan reaksi organ tubuh lain. Perubahan fungsional tekanan darah oleh kondisi stres dapat menyebabkan hipertropi kardiovaskuler menurut (Lawson, 2007 dalam Indah, 2015). Jadi dapat peneliti katakan bahwa stres sangat berpengahruh dalam kejadian hipertensi.

Hasil penlitian berikutnya di dukung oleh witasari, kadir, suhartatik (2014) dimana 36 responden terdapat 21 responden (58,3\%) yang mengalami stresdan 15 responden $(41,7$ $\%$ ) yang tidak mengalami stresdengan pvalue 0,002 bahwa adanya hubungan stres dengan kejadian hipertensi.

\section{SIMPULAN DAN SARAN}

Gangguan stres di wilayah kerja puskesmas sei pancur kota batam tahun 2018 stres mayoritas berada pada kategori stress sangat berat dengan jumlah 40 (62,3\%). Sedangkan Hipertensi di wilayah kerja puskesmas sei pancur kota batam tahun 2018, mayoritas berada pada kategori hipertensi dengan jumlah 56 (91,8\%).

Hasil analisa dengan menggunakan Man whitney terdapat hubungan yang signifikan antara hubungan stress dengan kejadian hipertensi di Puskesmas Sei Pancur Kota Batam Tahun 2018 Dengan nilai $\rho=0,001<0,05$

Saran dari penelitian ini diharapkan seluruh komponen kelurga dan masyarakat dengan sadar dan mau untuk membudayakan perilaku hidup sehat dan menjadikan kelurga yang bahagia dengan selalu berpikiran positif.

\section{DAFTAR PUSTAKA}

Ahmad khairudin. 2015. Hubungan stress dengan hipertensi anggota polri di sekolah polisi Negara Selopamioro, Yogyakarta.

Almatsier Sunita, 2010, Penuntun Diet, Edisi Baru, Gramedia, Jakarta.

Anna Palmer, 2007, Simpel Guide TekananDarah Tinggi, Erlangga, Jakarta.

Badan Pusat Statistik Provinsi Kepulauan Riau, (2016). Kepulauan Riau Province in Figures.

Bambang, Hartono, 2014, HipertensiThe Silent Killer,Perhimpunan Hipertensi Indonesia, Brunner \&Suddarth. (2013). Buku Ajar Keperawatan Medikal Bedah. Edisi 8 Vol 3. Jakarta : EGC

Penerbit: Poltekkes Kemenkes Padang, http://jurnal.poltekkespadang.ac.id/ojs/index.php/jsm 
Carlson Wade. (2016). First book on hypertension (High Blood Pressure) and diet, Keats Pub Inc.1975. Bandung

Chobanianet al, 2003, The Seventh Report of the Joint National Committee on Prevention, Detection, Evaluation, And Treatment of High Blood Pressure (JNC-VII), Jama 289:2560-2571.

Corwin. (2013). Hipertensi. Jakarta : EGC

Depkes RI, 2006, Pharmaceutical Care Untuk Penyakit Hipertensi, Direktorat Bina Farmasi Komunitas Dan Klinik, Ditjen Bina Kefarmasian Dan AlatKesehatan, Jakarta.

Dina T, Elperin, et al, 2013, A Large Cohort Study Evaluating Risk Factors Assosiated With Uncontrolled Hypertension, The Journal of Clinical Hypertension, Vol. 16 No. 2 Februari 2014.

Dinas Kesehatan Kota Batam, (2017). Data Penderita Hipertensi. Pemerintah Kota Batam.

Dinas Kesehatan Kota Batam, (2017). Data seluruh penderita hipertensi Kota Batam.

Pemerintah Kota Batam.

Dinas Kesehatan Provinsi Kepulauan Riau, (2015) :Batam Gunawan. (2012). Hipertensi, Jakarta: PT Gramedia

Gustina, Z.(2013). Faktor-faktor Stres Yang Berhubungan Dengan Tingkat Stres Mahasiswa Profesi Keperawatan Universitas Andalas Tahun 2013. Skripsi, Universitas Andalas, Fakultas Keperawatan, Padang

Hardjana . (1994). Stress tanpa distress. Yogyakarta: kanisius

Lawson, RW., Arthur, J., BarskyVictor, RG., Kaplan, NM. 2007. Systemic Hypertension: Mechanisms and Diagnosis. Philadelphia: Saunders Elsevier

Looker, Gregson. (2005). Managing stress: mengatasi stress secara mandiri Lovibon,S.H\&Lovibon, P.F. (1995). Manual for the Depression Anxiety \& Stress Scales

(Second edition). Psychology Foundation. Diakses dari www. Serene. Me. Uk.

Muhammad Saleha. 2014. Hubungan Tingkat Stress Dengan Derajat Hipertensi Pada Pasien Hipertensi Di Wilayah Kerja Puskesmas Andalas Padang.

Nursalam. (2014). Konsep dan Penerapan Metodologi Penelitian IImu Keperawatan.

Jakarta: Selemba Medika

Padila, (2013). Buku Ajar Keperawatan Medikal Bedah. Yogyakarta: Nuha Medika. Pusat data dan Informasi Kementerian Kesehatan RI 2013

Rosenthal,T\& Alter, A.(2011). Occupational Stres and Hypertension. Journal of the American Society of Hypertension, 6(1): 2-22

Rsentock $(1974,1977)$ Becker (1979) Health beliefe model kerangka konseptual 
Smeltzer S dan Bare B, 2014, Buku ajar keperawatan Medikal Bedah Brunner \&Suddarth edisi 8. Volume 2, EGC, Jakarta.

Witasari E, kadir A, Suhartatik 2014 hubungan antara stress dan polamakan dengan kejadian

World Health Organization. (2015). Hipertensi. [serial online][Agustus 2015].

Yimmi Syavardie 2014. Pengaruh stress terhadap kejadian hipertensi dipuskesmas matur, kabupaten agam. 